\title{
Towards innovative road cycle gloves for low vibration transmission
}

\author{
G. Sanseverino ${ }^{1,2} \cdot$ S. Schwanitz 2 D. Krumm ${ }^{2} \cdot$ S. Odenwald ${ }^{2} \cdot$ A. Lanzotti ${ }^{1}$ (I)
}

Received: 14 March 2020 / Accepted: 24 November 2020 / Published online: 8 February 2021

(c) The Author(s) 2021

\begin{abstract}
This research activity aims to develop new cycling gloves. A first step was focused on the definition of the functional requirements through user centred design methods. Since vibrations coming to the hand-arm system of a cyclist have a considerable effect a second step was concentrated on the analysis of hand-arm vibrations in road cycling. The paper shows results of laboratory tests executed for three different hand sizes, three different frequency ranges, with two different type of gloves and without gloves. Load conditions used for the test were determined with a former field test. Results obtained were analysed using Analysis of Variance (ANOVA), that showed no significant effect of existing gloves in reducing vibration transmissibility. This led to the need of new kind of cycling gloves that could reduce those vibrations and increase the cyclist's comfort.
\end{abstract}

Keywords Bioengineering $\cdot$ Sport equipment $\cdot$ Road cycling $\cdot$ Vibration transmission $\cdot$ Cycling gloves $\cdot$ User centred design $\cdot$ Design of experiments

\section{Introduction}

Most of recreational road cyclists perform rides that could be longer than $100 \mathrm{~km}$ and this mean that they cycle for more than $4 \mathrm{~h}$, this leads to the need of guarantee the cyclist's comfort. Bicycle's makers provide different size and shape of frames to best fit the customer's body and necessities; moreover, advanced bike-fitting tools have been developed to meet the individual biomechanics. All those expedients are not enough to give the right comfort to cyclists, protective devices as gloves play an essential role.

A. Lanzotti

antonio.lanzotti@unina.it

G. Sanseverino

giuseppe.sanseverino@mb.tu-chemnitz.de

S. Schwanitz

stefan.schwanitz@mb.tu-chemnitz.de

D. Krumm

dominik.krumm@mb.tu-chemnitz.de

S. Odenwald

stephan.odenwald@mb.tu-chemnitz.de

1 Fraunhofer JL Ideas-Department of Industrial Engineering, University of Naples Federico II, Naples, Italy

2 Department of Sports Equipment and Technology, Chemnitz University of Technology, 09107 Chemnitz, Germany
Cycling gloves serve several purposes, such as vibration absorption, better grip on the handlebars, protection from atmospheric conditions and protection in case of falling.

Vibrations induced from the road profile to the handlebar of a road bicycle affect the hand-arm system of cyclist, especially in certain condition of magnitude and frequency, these can lead to injuries and disorders (vascular disorders, neurological disorders, carpal tunnel syndrome and repetitive strain injuries). This is the reason why close attention to vibration absorption should be used when designing cycling gloves. Just few studies explore the effect of cycling gloves on vibrations transmission to the hand-arm system. Drouet et al. [1] studied the effect of cycling gloves and bar tape on vibrations transmission, this study showed a significant effect of bar tape in reducing the transmitted power and energy through the handlebar, but no significant effect of gloves.

The aim of this paper is to investigate the extent of hand-arm vibrations in road cycling, to test road cycling gloves and to develop innovative ones that reduce vibration transmission.

\section{User centred design}

Figure 1 shows the steps used in this work, which are all user centred [2]. 


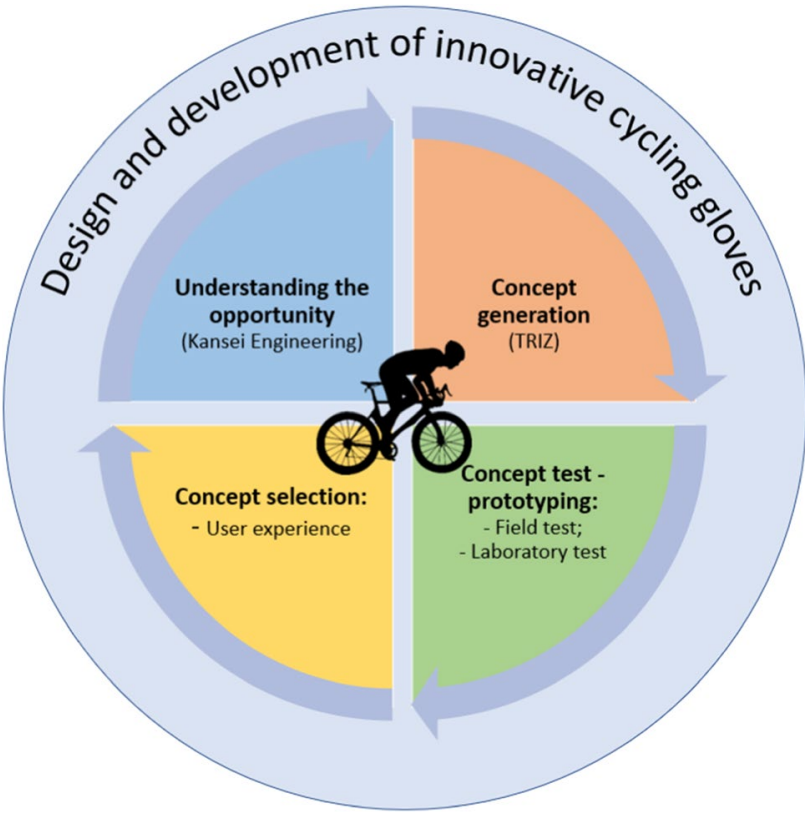

Fig. 1 User centred design scheme

According to the bases of Kansei engineering [3] a first survey, involving recreational cyclists, was carried out. It is divided into three main sections, the first aims to define the population, the second one is focused on the semantic domain exploration, interviewees were asked to describe the ideal cycling glove with some words (Kansei words) and the last explores the characteristics domain using Kano Model [4]. Most of respondents regularly use cycling gloves, but all of them found vibrations coming to the handlebar considerable and very annoying.

\section{Concept generation}

Results of the third part of the survey lays the foundation to concept generation and gives the Functional Requirements (FRs) that the product should have to fulfil users' needs.

Figure 2 shows the features that an optimal cycling glove should have, inner seams should be absent or at least hidden and visibility inserts for low light conditions should be provided. Moreover, it should reduce the vibrations coming to the hand-arm system providing a padding and in the same time the glove should guarantee a reduced thickness, this leads to a conflict. In fact, padded gloves currently on the market use a thick layer of gel or foam and most cyclists found that having this thick layer makes them lose the contact with the handlebar. To solve this conflict TRIZ method will be used.

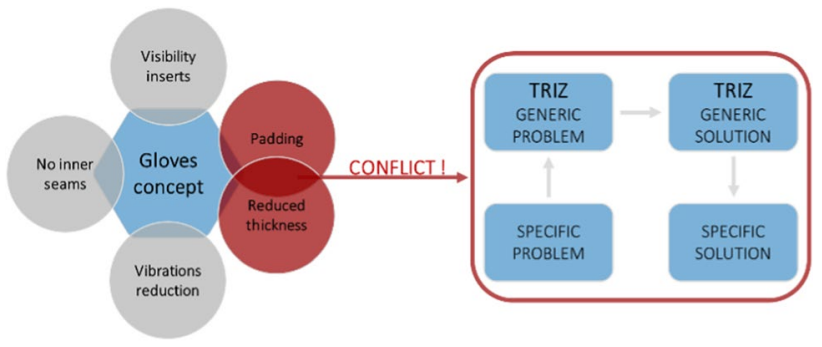

Fig. 2 Gloves concept generation

\section{Materials and methods}

Since hand-arm vibrations coming from the road profile represent an important issue for all cyclists involved, an analysis of those vibrations was necessary. Moreover, some tests focused on the effect of cycling gloves on those vibrations were made [5].

A first test has been performed on the field to define the extent of vibrations coming to the handlebar of a road bicycle [6]. The second study was carried out in the laboratory to quantify the transmissibility of different types of existing cycling gloves and to understand their effect on vibrations transmission.

Laboratory test consist of reproducing part of the acquired signal to a vibrating test machine, to submit those vibrations to different subjects and in different conditions and understand if there is a condition that has an effect in reducing vibrations induced to the hand-arm system. The test set-up (Fig. 3) comprised of a road handlebar, the same used for field trials, mounted to the hydraulic cylinder of a universal testing machine (HC 10, Zwick $\mathrm{GmbH}$ and Co. KG, Ulm, Germany), the same road bicycle used for field tests and a bicycle treadmill. To quantify the extent of vibrations coming to the handlebar and to the wrist, two triaxial ICP ${ }^{\circledR}$ accelerometers (354A04, PCB Piezotronics Europe GmbH, Hückelhoven, Germany), one mounted on the subject wrist joint and the other one at the end of the handlebar, were used.

Design of Experiments was used, three control factors and three level each were defined: Frequency ranges (A: 15-25 Hz; B: 35-45 Hz; C: 85-95 Hz); Hand circumference (S: $18.5-20.3 \mathrm{~cm}$; M: $20.3-22.2 \mathrm{~cm} \mathrm{~L}: 22.2-24 \mathrm{~cm}$ ); Hand equipment (NG: no gloves; NPG: non-padded gloves; PG: gel-padded gloves). A complete test schedule of 27 trials was obtained. Six volunteer subjects ( 1 female and 5 male) joined the test, two for each hand size. Each test was replicated 5 times in order to be more significant from a statistic point of view (Fig. 4).

Resulting acceleration of the three axes of each accelerometer was obtained and then filtered according to ISO 
Fig. 3 Laboratory test set-up

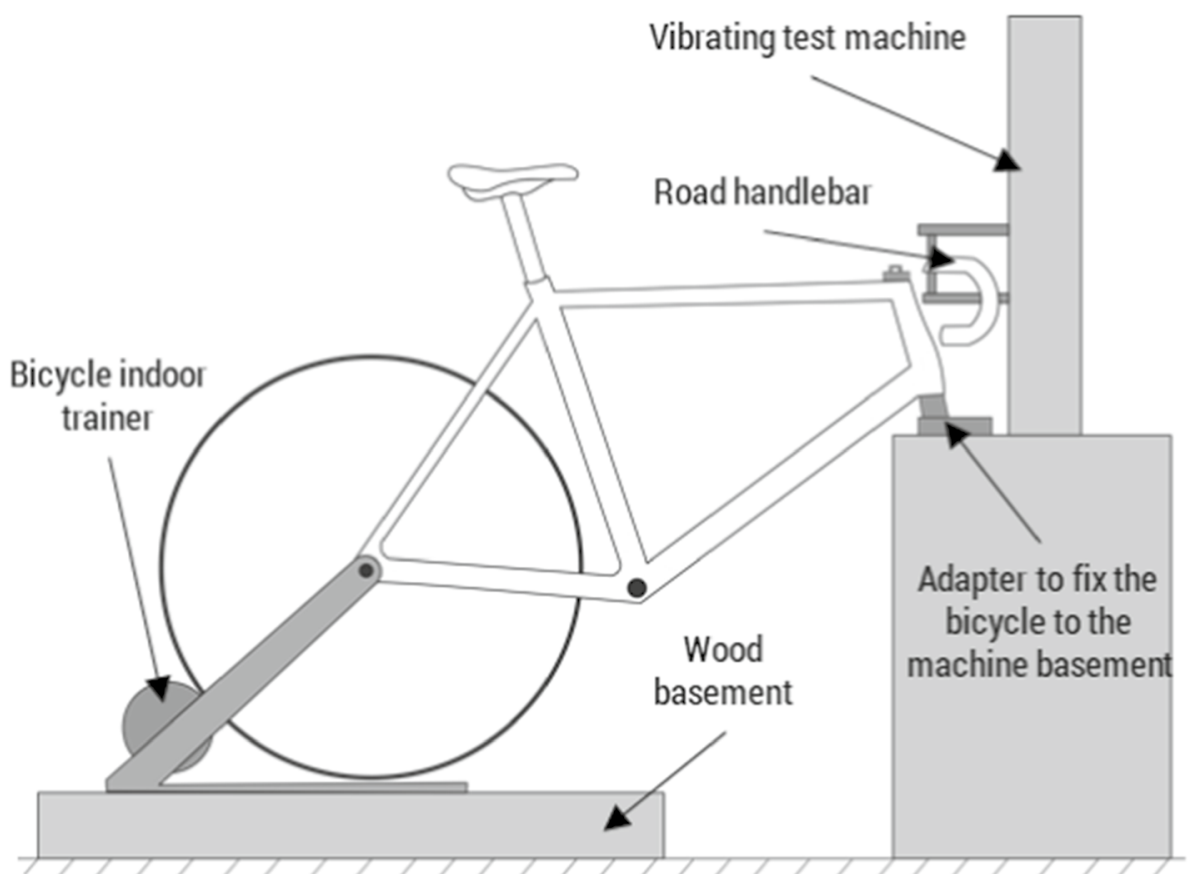

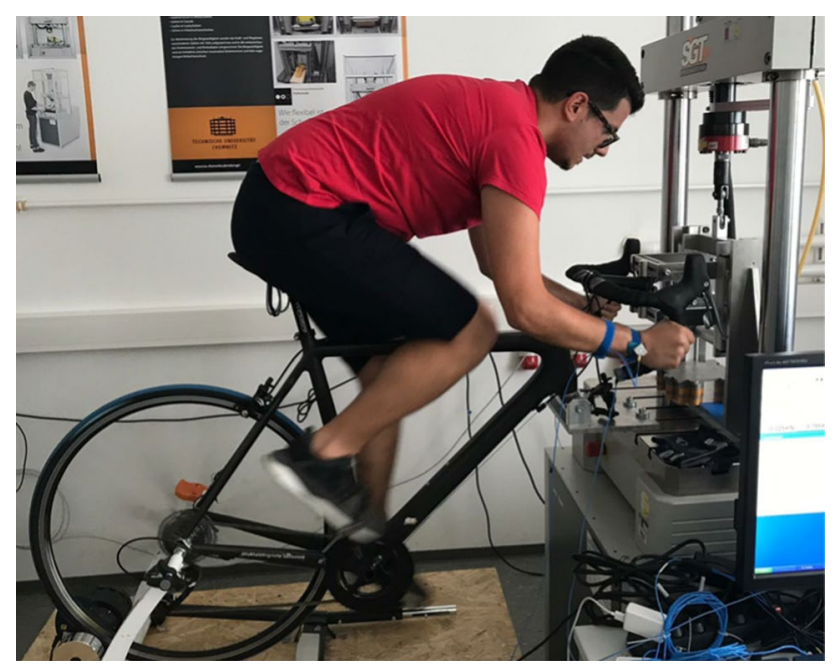

Fig. 4 Laboratory test execution

5349-1 to obtain the frequency-weighted accelerations, this allows to consider only the frequencies of vibrations that hand-arm system is more sensitive to (from 8 to $1000 \mathrm{~Hz}$ ), as a matter of fact it is designed to not affect those frequencies and to attenuate at those ones where the response of the body is less sensitive.

Once obtained the RMS values for each condition and each subject an arithmetic mean of the five replications made was calculated. The output RMS value, acquired on the wrist joint of the subject, was divided for the input one, recorded at the handlebar end, and thus obtained the transmissibility value used to analyse the results.
Table $1 p$ value for each load condition

\begin{tabular}{lll}
\hline Load condition & $\begin{array}{l}p \text { value (for hand } \\
\text { size })\end{array}$ & $\begin{array}{l}p \text { value (for } \\
\text { hand equip- } \\
\text { ment })\end{array}$ \\
\hline A $(d=0.98 \mathrm{~mm} ; \mathrm{f}=20 \mathrm{~Hz})$ & 0.269 & 0.005 \\
$\mathrm{~B}(\mathrm{~d}=0.71 \mathrm{~mm} ; \mathrm{f}=40 \mathrm{~Hz})$ & 0.326 & 0.767 \\
$\mathrm{C}(\mathrm{d}=0.08 \mathrm{~mm} ; \mathrm{f}=90 \mathrm{~Hz})$ & 0.587 & 0.725 \\
\hline
\end{tabular}

\section{Results and discussion}

Results in terms of transmissibility are investigated performing three separate ANOVA [7], one for each load condition. As it is possible to see in Table 1, only load condition A leads to a $p$ value that is under the threshold value $\alpha=0.05$, showing that hand equipment has a significant effect. Since the highest transmissibility value has been recorded with padded gloves this means that they had a negative effect in reducing vibration.

By analysing the cyclist's hand in the drops position, it is possible to note that the padded zones of the glove do not cover the contact area on the handlebar, this is showed in Fig. 5, where the contact zone is highlighted in red. This could explain why padded gloves have no effect.

\section{Concluding remarks and future works}

Results show that existing cycling gloves have no significant effect in attenuating vibrations coming from the road profile to the hand-arm system of a cyclist. The reason could be that 


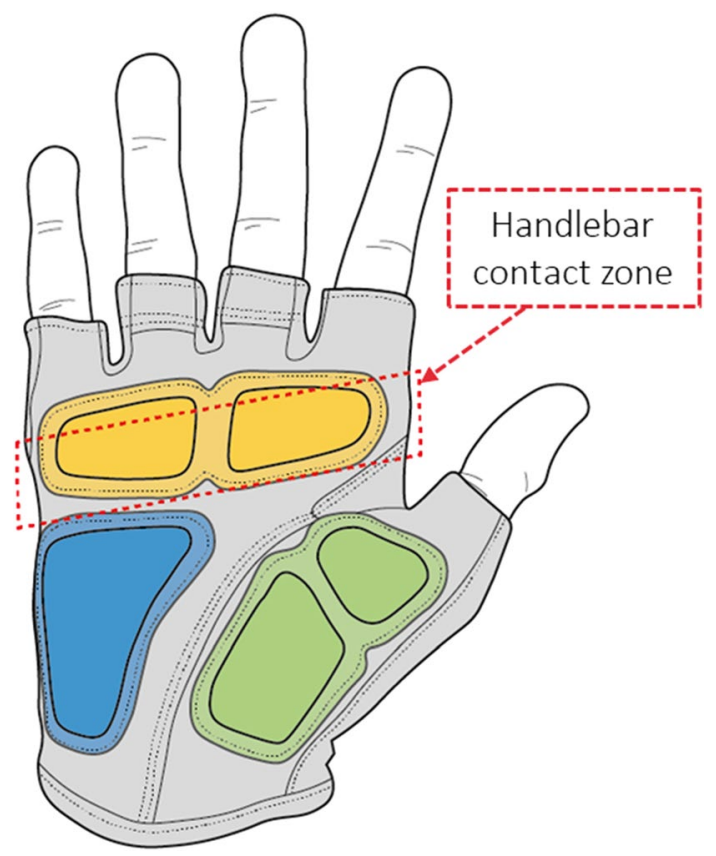

Fig. 5 Contact zone on the padded glove used for test

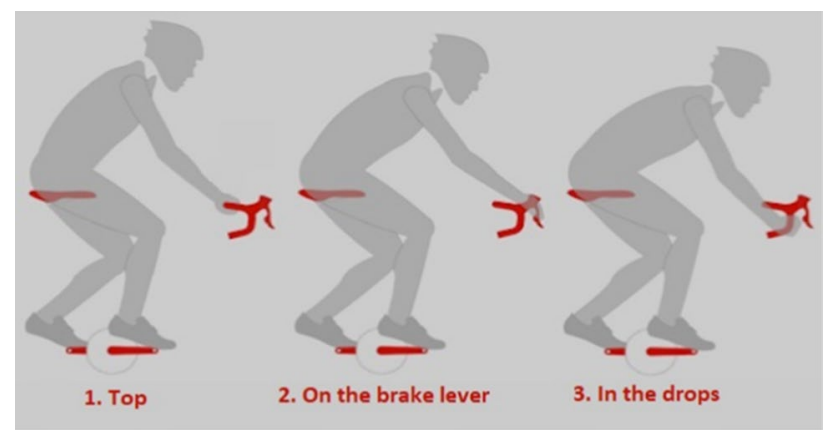

Fig. 6 Scheme of positions used on the handlebar

those cycling gloves are not designed to reduce vibrations and that the padding layout is not suitable for the position in the drops (Fig. 6) adopted in the test. In any case, surveys made show that the considered position is used from almost all the respondents while performing descent and vibrations could make the cyclist lose the contact with the handlebar and the brake levers with dangerous outcomes.

For these reason new cycling gloves should be designed paying close attention to hand-arm vibrations and their transmission, in order to raise the comfort and the safety of road cyclists.

Cyclists will be actively involved in the next design and prototyping phase. Design parameters will be adapted according to user experience and constantly monitored to ensure an interactive approach.
Acknowledgements G.S. traineeship was co-funded by the Erasmus+ Programme of the European Union. The activity was carried out in the international agreement program between Chemnitz University of Technology and University of Naples Federico II.

Funding Open Access funding provided by Università degli Studi di Napoli Federico II.

Open Access This article is licensed under a Creative Commons Attribution 4.0 International License, which permits use, sharing, adaptation, distribution and reproduction in any medium or format, as long as you give appropriate credit to the original author(s) and the source, provide a link to the Creative Commons licence, and indicate if changes were made. The images or other third party material in this article are included in the article's Creative Commons licence, unless indicated otherwise in a credit line to the material. If material is not included in the article's Creative Commons licence and your intended use is not permitted by statutory regulation or exceeds the permitted use, you will need to obtain permission directly from the copyright holder. To view a copy of this licence, visit http://creativecommons.org/licenses/by/4.0/.

\section{References}

1. Drouet, J.-M., Covill, D., Duarte, W.: On the exposure of hands to vibration in road cycling: an assessment of the effect of gloves and handlebar tape. In: Proceedings (2018). https://doi.org/10.3390/ proceedings 2060213

2. Kanai, S., Verlinden, J.: Advanced prototyping for human-centred design for information appliances. Int. J. Interact. Des. Manuf. (IJIDeM) (2009). https://doi.org/10.1007/s12008-009-0076-6

3. Lanzotti, A., Tarantino, P.: Kansei engineering approach for total quality design and continuous innovation. TQM J. (2008). https ://doi.org/10.1108/17542730810881311

4. Berger, C., Blauth, R., Boger, D., Bolster, C., Burchill, G., DuMouchel, W., Pouliot, F., Richter, R., Rubinhoff, A., Shen, D., Timko, M., Walden, D.: A special issue on Kano's methods for understanding customer-defined quality. Center Qual. Manag. J. 2(4):1-37 (1993)

5. Sanseverino, G., Schwanitz, S., Krumm, D., Odenwald, S., Lanzo$\mathrm{tti}, \mathrm{A} .:$ Understanding the effect of gloves on hand-arm vibrations in road cycling. In: Proceedings (2020). https://doi.org/10.3390/ proceedings 2020049070

6. Sanseverino, G., Schwanitz, S., Krumm, D., Odenwald, S., Lanzotti, A.: Understanding the effect of tire pressure and speed on vibrations transmission to the handlebar in road cycling. In: Fehr, U. (ed.) Zukunftsperspektiven von Sportinformatik \& Sporttechnologie im Leistungs- und Breitensport. 13. Symposium der dvsSektion Sportinformatik und Sporttechnologie. spinfortec2020 digital, "in Bayreuth", 24 and 25 September 2020, pp. 36-37 (2020)

7. Montgomery, D.C., Runger, G.C.: Design of experiments with several factors. In: Montgomery, D.C., Runger, G.C. (eds.) Applied Statistics and Probability for Engineers, 4th edn, pp. 538-617. Wiley, Hoboken (2006)

Publisher's Note Springer Nature remains neutral with regard to jurisdictional claims in published maps and institutional affiliations. 